\title{
Chasing the elusive cerebral autoregulation curve in pursuit of intraoperative brain protection
}

\author{
David L. Reich, MD, and Matthew A. Levin, MD
}

\footnotetext{
From the Department of Anesthesiology, Perioperative, and Pain Medicine, Icahn School of Medicine at Mount Sinai, The Mount Sinai Hospital, New York, NY.

Disclosures: Authors have nothing to disclose with regard to commercial support.

Received for publication May 9, 2017; accepted for publication May 18, 2017; available ahead of print June 13 , 2017.

Address for reprints: David L. Reich, MD, President and COO, The Mount Sinai Hospital, Horace W. Goldsmith Professor of Anesthesiology, Perioperative and Pain Medicine, Icahn School of Medicine at Mount Sinai, One Gustave L. Levy Place, Box 1010, New York, NY 10029 (E-mail: david.reich@mountsinai.org). J Thorac Cardiovasc Surg 2017;154:1599-600

$0022-5223 / \$ 36.00$

Copyright (C 2017 by The American Association for Thoracic Surgery

http://dx.doi.org/10.1016/j.jtcvs.2017.05.055
}

Cardiac surgeons, anesthesiologists, and cardiopulmonary perfusionists have worked collaboratively for decades to optimize cerebral outcomes after cardiac surgery. In a superb article published in this issue of the Journal, Hori and colleagues ${ }^{1}$ have combined data from several studies to address the question of whether the putative cerebral autoregulation curve can be observed and quantifiably monitored in clinical practice. And the answer is...sometimes yes, and sometimes no.

In the subset of patients in whom autoregulation was identified, there was significant variability among patients in their individual lower and upper limits of autoregulation. The sample average for optimal mean arterial pressure was below the lower limit in some patients and above the upper limit in others. The only reasonable conclusion is that clinicians cannot use demographic and disease-specific predictors to make a reliable determination a priori of the optimal mean arterial pressure range for any particular patient during cardiopulmonary bypass.

For practitioners of transcranial Doppler monitoring, the sense of reassurance that comes from continuous monitoring of cerebral blood flow velocity cannot be understated, nor can the anxiety of witnessing embolic phenomena and interruptions of cerebral perfusion during various surgical maneuvers and perfusion conditions. Yet there are real limitations in establishing and maintaining reliable monitoring in patients with ossified temporal bones and limited acoustic windows. The success rate of Hori and colleagues ${ }^{1}$ likely reflects an extraordinarily talented and experienced team of clinicians, and their experience may not be reproducible.

Transient blood pressure excursions outside the limits of cerebral autoregulation may have subtle effects on neurocognitive outcome. A prospective trial of transcranial Doppler monitoring-guided cerebral blood flow optimization versus protocolized mean arterial pressure control that assesses neurologic outcomes is a likely prerequisite for wider adoption. In the absence of such data, the maturation of other cerebral monitoring outcomes. $^{3-5}$

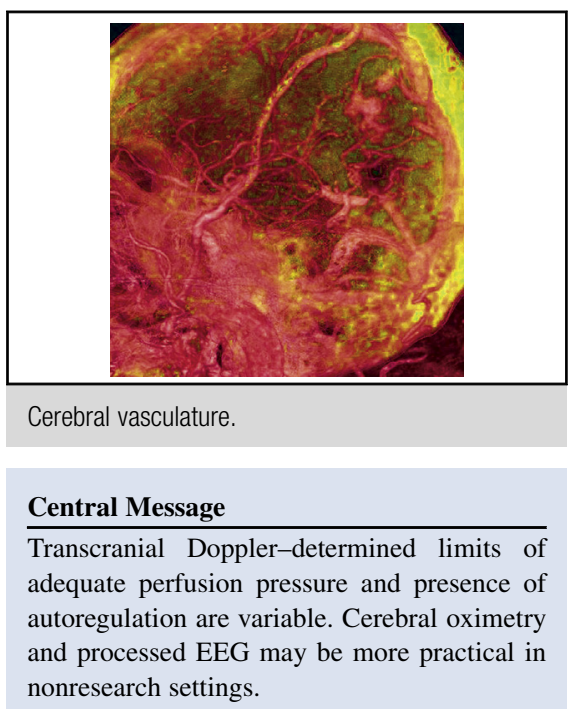

See Article page 1590.

technologies may provide alternatives to transcranial Doppler monitoring.

The evolution of near-infrared spectroscopy technology has resulted in the availability of several validated cerebral oximetry monitors. ${ }^{2}$ Although these measurements are also influenced by hemoglobin concentration, arterial and venous blood content, and cranial bone transmission, there is preliminary evidence that goal-directed therapy guided in part by cerebral oximetry has resulted in improved overall

Processed electroencephalography, such as bispectral index, may also be of value in cerebral monitoring during cardiac surgery. ${ }^{6-8}$ The sudden onset of an isoelectric electroencephalographic pattern or a marked change in electroencephalographic activity in the face of stable temperature and anesthetic concentrations may portend a cerebral event. 9,10 The ease of obtaining processed electroencephalographic signals in an era with markedly improved machine learning is an implicit call to action for researchers to identify whether limited channel electroencephalographic data are useful in guiding clinical care during cardiac surgery.

The complex interplay of underlying patient risk factors with perfusion pressure, hemodilution, anesthetic agents, $\mathrm{PaCO}_{2}, \mathrm{acid} / \mathrm{base}$ and temperature management, and myriad 
surgical interventions will continue to complicate the slow yet steady progress towards more effective brain protection during cardiac surgery. We are a bit wiser in that regard thanks to the efforts of Hori and colleagues. ${ }^{1}$

\section{References}

1. Hori D, Nomura H, Ono M, Joshi B, Mandal K, Cameron D, et al. Optimal blood pressure during cardiopulmonary bypass defined by cerebral autoregulation monitoring. J Thorac Cardiovasc Surg. 2017;154:1590-8.e2

2. Tortoriello TA, Stayer SA, Mott AR, McKenzie ED, Fraser CD, Andropoulos DB, et al. A noninvasive estimation of mixed venous oxygen saturation using near-infrared spectroscopy by cerebral oximetry in pediatric cardiac surgery patients. Paediatr Anaesth. 2005;15:495-503.

3. Murkin JM, Adams SJ, Novick RJ, Quantz M, Bainbridge D, Iglesias I, et al. Monitoring brain oxygen saturation during coronary bypass surgery: a randomized, prospective study. Anesth Analg. 2007;104:51-8.

4. Murkin JM, Murkin JM, Kamar M, Balberg M, Adams SJ. Intraoperative cerebral autoregulation assessment using ultrasound-tagged near-infrared-based cerebral blood flow in comparison to transcranial Doppler cerebral flow velocity: a pilot study. J Cardiothorac Vasc Anesth. 2015;29:1187-93.
5. Deschamps A, Hall R, Grocott H, Mazer CD, Choi PT, Turgeon AF, et al. Canadian Perioperative Anesthesia Clinical Trials Group. Cerebral oximetry monitoring to maintain normal cerebral oxygen saturation during high-risk cardiac surgery: a randomized controlled feasibility trial. Anesthesiology. 2016;124: 826-36.

6. Whitlock EL, Torres BA, Lin N, Helsten DL, Nadelson MR, Mashour GA, et al. Postoperative delirium in a substudy of cardiothoracic surgical patients in the BAG-RECALL clinical trial. Anesth Analg. 2014;118:809-17.

7. Soehle M, Dittmann A, Ellerkmann RK, Baumgarten G, Putensen C, Guenther U. Intraoperative burst suppression is associated with postoperative delirium following cardiac surgery: a prospective, observational study. BMC Anesthesiol. 2015;15:61.

8. Hu Z, Xu L, Zhu Z, Seal R, McQuillan PM. Effects of hypothermic cardiopulmonary bypass on internal jugular bulb venous oxygen saturation, cerebral oxygen saturation, and bispectral index in pediatric patients undergoing cardiac surgery: a prospective study. Medicine (Baltimore). 2016;95:e2483.

9. Toyama S, Sakai H, Ito S, Suzuki Y, Kondo Y. Cerebral hypoperfusion during pediatric cardiac surgery detected by combined bispectral index monitoring and transcranial Doppler ultrasonography. J Clin Anesth. 2011;23:498-501.

10. Kumar TV, Puri GD. Bispectral index as a possible early marker of cerebral hypoperfusion. Anesth Essays Res. 2013;7:405-7. 